\title{
Importancia de la diferenciación del enfoque diferencial étnico en el proceso de reparación en Bojayá, Chocó*
}

\author{
Importance of the differentiation of the ethnic differential approach \\ in the repair process in Bojayá-Chocó
}

Wanny Elizabeth Hinestroza-Ramírez**

\section{Resumen}

Objetivo. La aplicación del enfoque diferencial étnico en la reparación a víctimas negras tiene una trascendencia reivindicatoria de los derechos humanos como grupo, al constituirse como un instrumento de reconocimiento de sus particularidades culturales. Este artículo tiene como objetivo hacer una reflexión crítica a la aplicación de los principios y directrices que orientan la reparación en el derecho internacional, estudiando de manera particular el caso de Bojayá. Metodología. Para tales fines, la metodología que se empleó fue la revisión documental, a través de análisis de datos secundarios (estadística), estudio de contenido de documentos, textos, normas, jurisprudencias y doctrina. Resultado. La ejecución de planes de reparación afros sin atender el enfoque diferencial étnico se queda corto para satisfacer sus necesidades de reparación. Conclusión. Se concluye que en Bojayá los impactos generados por la aplicación de los estándares internacionales de reparación son relativamente bajos.

Palabras clave: enfoque diferencial étnico, reparación, víctimas, Bojayá, afrodescendientes.

\begin{abstract}
Objective: The implementation of the ethnic differential approach in the process of repair to black victims has a vindicating significance of human rights as a group, as it constitutes an instrument of recognition of their cultural particularities. This article aims to make a critical reflection on the application of the principles and guidelines that guide reparations in international law, particularly studying the case of the municipality of Bojayá. Methodology: For such purposes, the methodology used was the documentary review, through secondary data analysis (statistics), study of the content of documents, books, norms, jurisprudence, and doctrine. Results: Carrying out plans for the reparation of black communities without taking into consideration the ethnic differential approach falls short to meet their needs for reparation. Conclusion: It is concluded that the positive impacts obtained by the application of reparation according to international law standards in the municipality of Bojayá, are relatively low.
\end{abstract}

Key words: ethnic differential approach, reparation, victims, Bojaya, Afro-descendants

\footnotetext{
*Este artículo de reflexión se encuentra finalizado y se elaboró como requisito de grado en la Maestría en Derecho con énfasis en Derechos Humanos y Justicia Transicional de la Universidad del Rosario, y es el resultado de la investigación denominada "Reparación en Bojayá", donde se investigó todos los procesos de reparación adelantados por el gobierno de Colombia a la población de Bojayá, desde el acaecimiento de los hechos de la masacre, 02 de mayo de 2002.

*** Universidad Tecnológica del Chocó. Quibdó, Colombia. E-mail: wandiyi26@hotmail.com

(D) orcid.org/0000-0001-9378-5561 Google Scholar
} 
Importancia de la diferenciación del enfoque diferencial étnico en el proceso de reparación en Bojayá, Chocó

\section{Introducción}

La reparación para las comunidades afrodescendientes víctimas de la masacre de Bojayá es esencial, porque a través de ella se reivindican sus derechos como grupo étnico y puede considerarse un elemento que permita avanzar hacia la reestructuración de su vida comunitaria. Así, se hace necesario pensar en la inclusión de elementos con enfoque diferencial a fin de atender sus particularidades culturales y tradicionales, lograr el respeto a los derechos humanos y cumplir de manera plena el propósito de la reparación necesaria para las víctimas del conflicto.

Este artículo busca aportar elementos para proponer un debate sobre la reparación a grupos étnicos al identificar algunos vacíos en la dogmática y la jurisprudencia de reparaciones cuando se trata de violaciones a los derechos humanos de pueblos afrodescendientes. Por ello, además de determinar las necesidades específicas de reparación que tienen estos pueblos, partiendo de los reclamos de las víctimas, como lo abordan otros estudios ${ }^{1}$; se analiza cómo sus derechos se limitan desde la conceptualización y desarrollo de principios y directrices internacionales y de derecho interno colombiano de reparación, que no tienen en cuenta las particularidades culturales, ancestrales y tradicionales de su etnia, elementos esenciales para el ejercicio de los derechos humanos de este colectivo de personas.

Para sintetizar la reflexión, el presente texto pretende formular una crítica jurídica sobre los vacíos encontrados en las normas internacionales relativas a reparación cuando se trata de responder a necesidades de comunidades afrodescendientes, cuya cosmovisión del mundo y sus derechos distan de la visión general encontrada en la redacción y aplicación de estos.

La pregunta de investigación de este trabajo se plantea de esta forma: ¿cuáles son las directrices, principios internacionales y derecho interno colombiano relativos a reparación de víctimas de violaciones a derechos humanos y elementos diferenciales étnicos, que puedan responder a las necesidades específicas para la comunidad afrocolombiana en el caso de la masacre de Bojayá?

Para resolver la cuestión se realizó un trabajo documental tendiente a analizar datos secundarios (estadística), estudio de contenido de documentos, textos, normas, jurisprudencias y doctrina.

\footnotetext{
${ }^{1}$ Entre ellos se pueden referenciar a manera de ejemplo el estudio adelantado por Martha Nubia Bello, Elena Martín Cardinal, Constanza Millán Echeverría, Belky Pulido Hernández, Raquel Rojas Isaza (2005), llamado "Bojayá, memoria y río, violencia política, daño y reparación”, quienes indican que la alusión que hace la comunidad de Bojayá a la reparación es muy distante de la contemplada en el derecho internacional que toma el concepto en el sentido amplio, y sugieren tomar como punto de partida los estándares del DIH para el análisis de los usos del concepto que se hace en el país y de la variedad de acciones y propuestas realizadas en su nombre.
} 
Se utilizó un método deductivo porque se parte de nociones generales contenidas principalmente en las normas internacionales y nacionales (Pacto Internacional de Derechos Civiles y Políticos, Convención Americana sobre Derechos Humanos, Convención contra la Tortura y otros Tratos o Penas Crueles, Inhumanos o Degradantes, Resoluciones de la Asamblea General de la ONU, Constitución Política de Colombia de 1991 y Bloque de Constitucionalidad), para establecer conceptos como reparación integral, minorías étnicas y obligación de reparar. Además, de sentencias de la Corte Interamericana de Derechos Humanos (en adelante, la Corte IDH), Corte Constitucional y el Consejo de Estado sobre justicia y reparación integral a víctimas de violaciones de derechos humanos.

El desarrollo del artículo se compone de las siguientes partes: I. Se analizarán las sentencias de la Corte Interamericana de Derechos Humanos (en adelante la Corte IDH) sobre reparación a víctimas de graves violaciones a los derechos humanos, con especial atención a los fallos sobre grupos étnicos. 2. Se realizará una crítica analítica a la jurisprudencia del Consejo de Estado y la Corte Constitucional, en el tema de reparación por violación a los derechos humanos y se hará una especial reflexión a las sentencias sobre grupos étnicos. 3. Finalmente, se elaborará un breve análisis sobre los procesos de reparación adelantados en Bojayá a la luz de los principios y estándares internacionales y de la jurisprudencia internacional y de derecho interno colombiano.

\section{Discusión}

\section{Enfoque de la Corte Interamericana de Derechos Humanos en los casos de reparación}

La doctrina de las reparaciones en materia de derechos humanos ha enriquecido la disciplina del derecho internacional de los derechos humanos y ha proporcionado soluciones tangibles para garantizar justicia efectiva a víctimas concretas de violaciones. En este escenario, la creciente práctica judicial de creación y fortalecimiento de una dogmática de las reparaciones en materia de derechos humanos, ha sido una de las contribuciones modernas más importantes de esta rama del derecho, y la jurisprudencia interamericana ha jugado un papel fundamental para dinamizarla (Comisión Interamericana de Derecho Humanos, 2011, p.349).

La Convención Americana de Derechos Humanos (1969), en su artículo 63 establece: 1. Cuando decida que hubo violación de un derecho o libertad protegidos en esta Convención, la Corte dispondrá que se garantice al lesionado en el goce de su 
derecho o libertad conculcados. Dispondrá, asimismo, si ello fuera procedente, que se reparen las consecuencias de la medida o situación que ha configurado la vulneración de esos derechos y el pago de una justa indemnización a la parte lesionada. 2. En casos de extrema gravedad y urgencia, y cuando se haga necesario evitar daños irreparables a las personas, la Corte, en los asuntos que esté conociendo, podrá tomar las medidas provisionales que considere pertinentes. Si se tratare de asuntos que aún no estén sometidos a su conocimiento, podrá actuar a solicitud de la Comisión (Convención Americana de Derechos Humanos, 1969, art. 63).

La Corte IDH ha conceptualizado la reparación en aplicación de la Convención Americana sobre Derechos Humanos de la siguiente manera:

La reparación del daño ocasionado por la infracción de una obligación internacional requiere, siempre que sea posible, la plena restitución (restitutio in integrum), la cual consiste en el restablecimiento de la situación anterior. De no ser esto posible, como en el presente caso, cabe al tribunal internacional determinar una serie de medidas para, además de garantizar los derechos conculcados, reparar las consecuencias que las infracciones produjeron, así como establecer el pago de una indemnización como compensación por los daños ocasionados. (Caso Cantoral Benavides vs. Perú, 2001, p. 2)

En esta sentencia, la Corte IDH dejó planteadas las bases sobre las cuales deben regirse las reparaciones por violación a los derechos humanos. Es decir, inicialmente se debe procurar volver a la situación antes de ocurrencia del daño, cuando esto no sea posible se deben tomar las otras medidas que el derecho internacional de los derechos humanos nos presenta como la satisfacción, rehabilitación, garantías de no repetición e indemnización.

En la sentencia Loayza Tamayo vs. Perú (1998), la Corte IDH indica que "la reparación es el termino genérico que comprende las diferentes formas como un Estado puede hacer frente a la responsabilidad internacional en que ha incurrido restitutio in integrum, indemnización, satisfacción, garantías de no repetición, entre otras" (p. 2).

Con las dos sentencias mencionadas, se establece el panorama interamericano de garantía y eficacia del derecho a la reparación de las víctimas de violaciones a sus derechos humanos. 
En esa misma sentencia, en el voto razonado conjunto de los jueces A.A Cançado Trindade y A. Abreu Burelli (1998) se aclara que:

Por ello concluyen que todo el capítulo de las reparaciones de violaciones de derechos humanos debe, a nuestro juicio, ser repensado desde la perspectiva de la integralidad de la personalidad de la víctima y teniendo presente su realización como ser humano y la restauración de su dignidad. La presente Sentencia de reparaciones en el caso Loayza Tamayo, al reconocer la existencia del daño al proyecto de vida vinculado a la satisfacción, entre otras medidas de reparación, da un paso acertado y alentador en esta dirección, que, confiamos, será objeto de mayor desarrollo jurisprudencial en el futuro. (p. 40)

La Corte IDH ha avanzado mucho en el tema de reparación integral de las víctimas de violaciones a los derechos humanos, actualizando día a día su jurisprudencia y ajustándola a las necesidades de cada caso. Sin embargo, como lo reconocen los jueces A.A Cançado Trindade y A. Abreu Burelli se necesita un mayor desarrollo jurisprudencial y precisión en las sentencias, para que en el proceso de analizar las reparaciones desde la integralidad de la víctima su realización como ser humano y un enfoque diferencial étnico, se logre reconocer las particularidades de los diferentes grupos y minorías sujetos de especial protección, y se cumpla el fin último de restaurar la dignidad de las víctimas, sin afectar el libre desarrollo de la personalidad y su cosmovisión del mundo.

\section{Ordenes de reparación de la corte IDH en casos de grupos étnicos}

Además de repensarse la reparación en el Derecho Internacional de los Derechos Humanos desde la perspectiva de la integralidad de la persona de la víctima y teniendo en cuenta su realización como ser humano, se debe, dependiendo el caso, atender las particularidades culturales y tradicionales de las víctimas y su relación espiritual con los bienes patrimoniales y no patrimoniales perdidos, como consecuencia de la violación a sus derechos humanos, es decir, aplicar un enfoque diferencial étnico.

En relación con el punto anterior, Rojas (2009) precisa que la "Corte Interamericana en la sentencia Moiwana vs Suriname incorporó elementos culturales al momento de fijar el daño inmaterial” (p. 53). Dado que las víctimas del presente caso son miembros de la cultura N'djuka, este Tribunal considera que las reparaciones individuales determinadas deben complementarse con medidas ordenadas a favor de la comunidad como un todo (Moiwana vs Suriname, 2005, p. 79). 


\begin{abstract}
En otra sentencia, la Corte IDH ordena como media de reparación además de las pecuniarias, un acto público de reconocimiento de responsabilidad internacional, en desagravio de las víctimas y en memoria de las personas ejecutadas en la masacre que debe realizarse en la Aldea de Plan de Sánchez. En ese acto, el Estado debe tomar en cuenta las tradiciones y costumbres de los miembros de las comunidades afectadas [énfasis agregado]. Además, ordenó medidas como el estudio y difusión de la cultura maya achí en las comunidades afectadas a través de la Academia de Lenguas Mayas de Guatemala u otra organización similar, dotación de personal docente capacitado en enseñanza intercultural y bilingüe en la educación primaria, secundaria y diversificada de dichas comunidades. Con el objetivo de propender por la conservación de la cultura y tradiciones de estas poblaciones (Corte Interamericana de Derechos Humanos, caso Plan de Sánchez vs Guatemala, 2004, s.p).
\end{abstract}

En otros casos como el de la Comunidad Indígena XákmokKásek. vs. Paraguay (2010), Caso Pueblo Indígena Kichwa de Sarayaku vs. Ecuador de 2012, ordena crear fondo de Desarrollo Comunitario, el cual es organizado por el Estado en coordinación con las comunidades víctimas y busca atender necesidades culturales y de desarrollo de la comunidad.

En los diferentes fallos de la Corte IDH sobre derechos de las minorías étnicas se refleja que aborda con una dogmática clara y significativa los derechos especiales de estas comunidades e indica que se deben atender a sus particularidades para definir los mecanismos de reparación sobre todo del daño inmaterial, sin embargo, al ordenar medidas concretas de reparación para la reivindicación de las costumbres y tradiciones de los pueblos indígenas y tribales, se queda corta, ordenando medidas indemnizatorias. Ejemplo de la anterior afirmación, se encuentra en el Caso del Pueblo Saramaka. vs. Surinam (2007), donde la Corte IDH decide que:

Existe prueba que indica el sufrimiento y la angustia que el pueblo Saramaka ha atravesado como resultado de una larga y continua lucha por el reconocimiento legal de su derecho al territorio que tradicionalmente han ocupado y utilizado durante siglos [...]. Todo ello constituye una denigración de sus valores culturales y espirituales. La Corte considera que el daño inmaterial que estas alteraciones causaron en el tejido de la sociedad misma del pueblo Saramaka les da el derecho de obtener una justa indemnización. (p. 62) 
A pesar del desarrollo jurisprudencial de la Corte IDH, en los fallos mencionados anteriormente, en el caso de las Comunidades Afrodescendientes desplazadas de la cuenca del río Cacarica (Operación Génesis) vs. Colombia (2013), las órdenes de reparación fueron muy restringidas, para tratarse de violación a derechos humanos de comunidades negras. En este caso, los representantes y la comisión solicitaron entre otras medidas:

Como medidas encaminadas al mantenimiento de la Cultura Afrocolombiana y sus Tradiciones: a) la publicación de un libro, la elaboración de una película y una serie radial; b) Plan de Fortalecimiento de su Identidad Cultural, creación de casas de la cultura en cada asentamiento, y c) otras medidas relacionadas. Adicionalmente solicitaron medidas relativas a la construcción y mantenimiento de museos y monumentos: d) la construcción del Museo de la Afrocolombianidad en Bogotá con una réplica en Cacarica; e) la financiación del proyecto de monumento "en memoria de Marino López” y "por el desplazamiento forzoso en 5 puntos”, y f) la conservación y el reconocimiento respecto de los monumentos ya existentes. La Corte decidió que no considera necesario ordenar las medidas solicitadas por los representantes, ya que la emisión de la presente Sentencia y las reparaciones ordenadas en la misma resultan suficientes y adecuadas. (p. 148)

Se analiza que la Corte IDH, en los casos fallados sobre grupos étnicos, ha ido incorporando medidas de satisfacción que responden a la necesidad de conservación de la cultura y cosmovisión de los pueblos indígenas. Pero, en situaciones donde los fallos favorecen a la comunidad afrodescendiente, es mucho más restrictiva de sus derechos colectivos. Por ejemplo, el fallo analizado no corresponde a las necesidades particulares de reparación exigidas por las víctimas.

Falta adentrarse a las condiciones de vida de los pueblos negros para entender sus exigencias de reparaciones tan específicas, y cuál es el objetivo que persiguen con ellas, la reconstrucción comunitaria tradicional. Esto no se logra con la aplicación de los estándares de reparación internacionales, cuando no se aplica el enfoque étnico.

\section{La reparación en el derecho interno colombiano}

El Estado colombiano a través de la jurisprudencia del Consejo de Estado y la Corte Constitucional ha realizado el control de convencionalidad en la aplicación del derecho de reparación a víctimas de violaciones de los derechos humanos. Además, al tratarse de las sentencias de constitucionalidad, la Corte Constitucional ha realizado el control de legalidad conforme al bloque de constitucionalidad como se verá a continuación. 
Importancia de la diferenciación del enfoque diferencial étnico en el proceso de reparación en Bojayá, Chocó

\section{El enfoque diferencial}

El enfoque diferencial puede entenderse como el conjunto de acciones que, al dar un trato diferenciado a algunos grupos poblacionales, contribuye a reducir la brecha existente entre los diferentes segmentos de la población y garantiza la superación de la exclusión social, la marginalidad política, la desigualdad económica, la condición especial de vulnerabilidad y el riesgo de estas poblaciones ante el conflicto armado, lo que genera igualdad en el acceso a las oportunidades sociales. (Ministerio del Interior, s.f., p. 7)

\section{Reparación en el Consejo de Estado}

El derecho administrativo ha sido una marcha nazarena en Colombia: un paso adelante, dos para atrás. A partir del 2007 se empezaron a incluir en Colombia conceptos como cosa juzgada internacional, es decir, que las sentencias que decide la Corte IDH tienen fuerza vinculante y no pueden ser falladas nuevamente. Además de la cosa juzgada internacional, se empezó a fallar por parte del máximo órgano de la jurisdicción administrativa, otorgando reparaciones tanto pecuniarias como no pecuniarias en temas administrativos (Vásquez, 2016, p. 36).

Pero solo en 2008, a través de la Sentencia del 20 de febrero, Exp 16.996, el Consejo de Estado, modificó su clásico sistema indemnizatorio, apelando a los criterios de la Corte Interamericana de Derechos Humanos y luego en decisiones de la Asamblea General de las Naciones Unidas, donde se construyó internamente una línea jurisprudencial (Vásquez, 2016, p. 36).

A partir de esta Sentencia, el Consejo de Estado aplicó control de convencionalidad y otorgó medidas de reparación como satisfacción, rehabilitación y garantías de no repetición en casos de violaciones a los derechos humanos.

Asimismo, el Consejo de Estado en la sentencia sobre falsos positivos además de ordenar medidas de reparación pecuniarias, determinó medidas de satisfacción como publicación de la sentencia en la página oficial del ejército y el Ministerio de Defensa, la publicación en un periódico de amplia circulación nacional y local de Cajamarca los apartes de la sentencia referidos a la víctima, la rectificación de la verdadera identidad del señor 
Camilo Pulido Pulido y el reconocimiento de su ejecución extrajudicial. Lo anterior en virtud de la imposibilidad de garantizar la restitutio in integrum del daño. (Consejo de Estado, sala de lo contencioso administrativo, Sentencia 35029, 2016)

Pese al desarrollo jurisprudencial del Consejo de Estado en la reparación integral y la aplicación de justicia restaurativa a casos que no comprenden violación a derechos humanos, respecto a la reparación de los daños por violaciones a los derechos humanos de comunidades negras, no se encuentra desarrollo jurisprudencial.

Lo anterior causa mucha preocupación debido a que tal como lo advierte la Comisión Interamericana de Derechos Humanos (2013) se "corroboró el impacto desproporcionado de la violencia y el desplazamiento forzado para las personas afrodescendientes (p.262). Esto permite concluir que siendo la población negra una de las más afectadas por la violencia en Colombia, los casos específicos de vulneración a sus derechos no han sido tramitados por el Consejo de Estado, máxima autoridad de la jurisdicción administrativa en Colombia.

Se informó que el $50 \%$ de la población de Chocó ha sido víctima del conflicto, mientras que el Defensor del Pueblo destacó que la continuidad de los enfrentamientos y la violencia ha incrementado el número de territorios minados, así como el fenómeno del desplazamiento forzado, las desapariciones, masacres, ejecuciones extrajudiciales y el reclutamiento de NNA (Comisión Interamericana de Derechos Humanos, 2013).

Se sintetiza que los casos de graves violaciones de derechos humanos a comunidades negras por el conflicto armado y su situación de exclusión no han sido analizados por el Consejo de Estado y, por lo tanto, a esta población el Estado colombiano, a través del máximo órgano de la jurisdicción administrativa, no le ha reconocido medidas de justicia restaurativa, ni una reparación integral.

\section{La reparación en la Corte Constitucional}

La Corte Constitucional en la Sentencia C-1199 del 2008 establece que:

La reparación: i) incluye todas las acciones necesarias y conducentes a hacer desaparecer, en la medida en que ello sea posible, los efectos del delito; ii) al igual que el concepto de víctima tiene una dimensión tanto individual como colectiva; iii) no se agota en su perspectiva puramente económica, sino que 
Importancia de la diferenciación del enfoque diferencial étnico en el proceso de reparación en Bojayá, Chocó

tiene diversas manifestaciones tanto materiales como simbólicas y iv) es una responsabilidad que atañe principalmente a los perpetradores de los delitos que dan lugar a ella, pero también al Estado, particularmente en lo relacionado con algunos de sus componentes.

Tratándose de grupos étnicos, la Corte Constitucional en el Auto 005 de 2009 manifestó que:

El punto de partida y el fundamento común de la presente providencia es el carácter de sujetos de especial protección constitucional que tienen las comunidades afro descendientes. Esta condición de sujetos de especial protección impone a las autoridades estatales a todo nivel, respecto de la población afro colombiana víctima de desplazamiento forzado, especiales deberes de prevención, atención y salvaguarda de sus derechos individuales y colectivos, a cuyo cumplimiento deben prestar particular diligencia. Tal carácter de sujetos de especial protección constitucional justifica la adopción de medidas de diferenciación positiva, que atiendan a sus condiciones de especial vulnerabilidad e indefensión y propendan, a través de un trato preferente, por materializar el goce efectivo de sus derechos. (Numeral 10)

Asimismo, la Corte Constitucional, ordenó que las políticas públicas sobre desplazamiento tuvieran un "enfoque diferencial" para la población afrocolombiana. El enfoque diferencial debe garantizar que la atención humanitaria, los programas sociales y las políticas de verdad, justicia, reparación y no repetición para los grupos étnicos protejan su identidad cultural y la relación colectiva con el territorio que ella comprende. (Corte Constitucional, auto 005, 2009)

La Corte Constitucional ha realizado un avance significativo en el derecho a la reparación integral de las víctimas de graves violaciones a los derechos humanos, sin embargo, no hay desarrollo jurisprudencial de esta alta corte cuando se trata de grupos étnicos, especialmente comunidades afrodescendientes, a pesar de que, como se indicó, y ella misma lo ha reiterado en sus sentencias (entre otras la T-1095 de 2005. MP. Clara Inés Vargas Hernández, C-169 de 2001. MP. Carlos Gaviria Díaz y T-422 de 1996. MP. Eduardo Cifuentes Muñoz), "la situación de histórica marginalidad y segregación que han afrontado los afrocolombianos" (Corte Constitucional, Auto 005 de 2009). 
La Corte Constitucional ha propendido por el reconocimiento de los derechos de los negros como grupos de especial protección constitucional y la necesidad de políticas y acciones afirmativas diferenciadas para esta comunidad, atendiendo su cultura y tradición para el tema de reparación integral. Pero no ha indicado órdenes concretas de aplicación de las acciones afirmativas, ni diferenciadas, por lo que el concepto de enfoque diferencial reconocido por la corte y las políticas públicas del gobierno colombiano sigue siendo muy indefinidos.

En Colombia es relevante que todos los jueces de la república apliquen los instrumentos internacionales de reparación a los daños sufridos por víctimas del conflicto armado en sus decisiones, que en las sentencias se empleen mecanismos de justicia restaurativa y enfoques diferenciales, porque todos los casos no son conocidos por las altas cortes y es necesario que en la primera escala de protección de derechos humanos no se deniegue justicia, y los principios internacionales de reparación a víctimas de violación a sus derechos humanos con enfoque étnico se les garanticen desde las primeras sentencias.

\section{La reparación en la comunidad de Bojayá}

El municipio de Bojayá tiene una situación económica y social difícil. El departamento del Chocó ha sido excluido y discriminado a lo largo de su historia. Aunado a ello, en el actual proceso de paz firmado en La Habana se acordaron medidas de justicia transicional que deben desencadenar en una transición política, el gobierno indicó explícitamente que el sistema económico del Estado no era objeto de discusión, por lo tanto no se modificaba. Ello da lugar a entender que este proceso no se está haciendo cargo de las injusticias sociales y económicas históricas como las sufridas en Bojayá, y su alcance es limitado y estricto, debido a que indaga por la verdad, pretende castigar simbólicamente a algunos de los responsables de las atrocidades, garantizar una reparación a las víctimas y ofrecer garantías de no repetición, dejando de un lado el concepto amplio de justicia transicional que implicaría medidas sociales, económicas y políticas, garantizando a la población un goce pleno de sus derechos.

En el proceso transicional surtido entre el gobierno de Colombia y las Fuerzas Armadas Revolucionarias (FARC) se acordó un punto relativo a la reparación de víctimas. Sin embargo, para el caso de Bojayá el desarrollo de dichas medidas de reparación entra en tensión con los intereses de los miembros de la sociedad que no son víctimas del conflicto, pero sí de la exclusión y abandono estatal de años. Debido a que, por un lado está un pueblo sumido en la pobreza, la exclusión y la discriminación y, por el otro, habitantes en las mismas condiciones pero que además sufrieron una tragedia que da lugar a la reparación integral.

El aspecto de la justicia transicional que se requiere impactar, en el caso específico de Bojayá, es el tema de la reparación integral y para ello es necesario enfatizar la aplicación de los 
Importancia de la diferenciación del enfoque diferencial étnico en el proceso de reparación en Bojayá, Chocó

mecanismos de reparación con un enfoque étnico, porque es una de las formas como se reivindican los derechos de las víctimas que no solo esperan compensaciones económicas para sentirse reparadas.

Para estudiar el proceso de reparación a las víctimas de Bojayá se partió del reconocimiento de sus habitantes como grupo étnico, soportado en la sentencia de la Corte Constitucional C-169 de 2001:

Un objetivo a saber, la existencia de rasgos culturales y sociales compartidos por los miembros del grupo que les diferencia de los demás sectores sociales. Y un elemento subjetivo, esto es, la existencia de una identidad grupal que lleve los individuos a asumirse como miembros de la colectividad en cuestión. Por lo tanto, los derechos colectivos de las comunidades negras en Colombia son una función de su estatus en tanto grupo étnico, portador de una identidad propia que es digna de ser protegida y realzada, y no del color de la piel de sus integrantes.

\section{Mecanismos de reparación}

La reparación integral comprende medidas de restitución, indemnización, rehabilitación y satisfacción, así como medidas dirigidas a evitar la repetición de las violaciones.

\section{Acciones de restitución}

El Estado colombiano adelantó varias acciones afirmativas en la comunidad: Proyecto de Reubicación de Bellavista, el cual integró como medida la recuperación social del territorio; expedición del CONPES 3169 para la asignación de 5.000 millones de pesos del Presupuesto General de la Nación para la reconstrucción de Bojayá y el CONPES 3180, contentivo del programa para la reconstrucción y el desarrollo sostenible del Urabá antioqueño y chocoano y el Bajo y Medio Atrato, como expresión de la política para la población afrocolombiana. (Lozano, 2010, p. 469)

La reubicación de la comunidad a un sitio diferente del lugar donde tradicionalmente estaba localizado, por haber sido focalizada como zona de alto riesgo de inundación, implicó para estas el desarraigo de su territorio, evidenciable por el abandono del antiguo Bojayá, al encontrarse lejos del nuevo Bellavista y solo se visita cada 2 de mayo, cuando se rememora la masacre. 
Para lograr el objetivo reparador del mecanismo de restitución, las acciones desarrolladas por el Estado en la atención de las víctimas de Bojayá debieron atender sus particularidades étnicas, esto es, su forma de organización, tradiciones, cultura y desarrollo comunitario. Porque implementar la restitución in integrum, como lo establece el derecho internacional (devolver a la víctima a la situación anterior a la violación manifiesta de las normas internacionales de derechos humanos), tiene una relevancia para las comunidades afrodescendientes por el arraigo que tienen con su territorio, lo cual se garantiza permitiendo un goce pleno de su territorio ancestral de manera libre, sin la amenaza de los grupos armados, que puedan apropiarse de los recursos naturales que ancestralmente han sustentado sus familias y desarrollado una vida comunitaria.

Es relevante escuchar a las víctimas, incluirlas en las discusiones sobre los temas que las afectan, realizar un trabajo organizado y complementario entre las diferentes instituciones del Estado, para conseguir una plena y verdadera reparación que aborde los problemas de los afectados y garanticen una justicia distributiva y restaurativa. Todo lo anterior, partiendo de las particularidades de los grupos y minorías étnicas como la afrodescendiente.

Pero debe tenerse en cuenta que, por las condiciones de exclusión y pobreza en la que históricamente han vivido, devolver a las víctimas a la situación anterior a la violación de sus derechos humanos, sin adoptar al mismo tiempo medidas de satisfacción y garantías de no repetición, significaría regresarlos a una situación de marginalidad y pobreza mayor a la que tenían antes.

De lo anterior se infiere que las prestaciones ejecutadas fueron concebidas por los receptores de estas como medidas de inversión social focalizadas, distinto del mecanismo de reparación establecido en la norma.

\section{Acciones de indemnización}

Frente al mecanismo de indemnización, en la jurisdicción administrativa se han fallado diferentes casos tendientes a lograr la compensación a las víctimas de Bojayá, realizado un inventario de los casos existentes, se encontró que entre 2012 y 2016 han sido presentadas y falladas cinco demandas relacionadas con reparación directa para 123 beneficiarios, valoradas en 191.000 millones de pesos y 10.800 s.m.l.m.v. (anexo 1). Además de los fallos relacionados, existen varias demandas de reparación y acciones de grupo que aún no han sido falladas y que incluyen más de 100 familias.

La indemnización se ha centrado exclusivamente en lo material y lo económico, perdiendo de vista elementos fundamentales como el fortalecimiento del "nosotros", que plantea el resarcimiento del interés común y lo cultural-social que debe privilegiarse en culturas como 
la indígena y la afrocolombiana (Bello, Martín, Millán, Pulido y Rojas, 2005, p. 138); dando lugar al fraccionamiento de la comunidad entre los que han recibido plata por sus muertos y los que siendo víctimas, no tienen derecho a una reparación económica.

En la actualidad ya se evidencian resistencias, lo anterior porque el Estado ha implementado reparaciones individuales a algunas víctimas y ayudas humanitarias a 88 familias; pero muchos habitantes de corregimientos vecinos y miembros de la misma población, no víctimas directas de la masacre, no están conformes con los procedimientos de reparación adelantados por el Estado, consideran que sus derechos históricamente han sido desconocidos y las necesidades básicas están insatisfechas.

Partiendo del enfoque de desarrollo expuesto por el economista Amartya Sen (2000), se puede aunar los esfuerzos para lograr tanto el mejoramiento de la calidad de vida de esta comunidad y una efectiva reparación proporcional al daño sufrido, buscando el punto de convergencia entre las políticas públicas y los programas de reparación que permitan tomar ventaja de la guerra y poder garantizarle un mejor bienestar a la población de Bojayá. Sin reemplazar el desarrollo por la reparación, o viceversa, no puede ser cuestión de escoger una de dos, debe realizarse paralelamente una con la otra.

\section{Acciones de satisfacción}

Frente al mecanismo de satisfacción, el Estado colombiano ha realizado esfuerzos por ajustar sus políticas y estrategias a los estándares internacionales sobre reparación, mediante la protocolización del Plan Integral de Reparación Colectiva que vinculó a 1.100 personas de la comunidad de Bellavista; este contempla como medida de dignificación que la unidad de víctimas liderará actos de conmemoración el 2 de mayo, durante tres años. Para recuperar el tejido social: retomar celebraciones del día del campesino, el día intercultural de la hermandad y las fiestas patronales el 16 de julio. Se creará la escuela de transmisión de saberes ancestrales de rezanderas, cantadoras, curanderos, parteras para recuperar prácticas culturales y tradicionales (Unidad de Víctimas, 2018).

Asimismo, con el proceso de paz firmado entre el Estado colombiano y las FARC, se pudo adelantar una reparación colectiva, consistente en la pedida pública de perdón de las FARC por los hechos de la masacre en Bojayá, y delante las víctimas sobrevivientes por unos de los miembros de la extinta guerrilla, Pastor Alape. Sin embargo, este hecho simbólico aún no cumple con el objetivo de reparación debido a que ni el Estado, ni los paramilitares, han realizado este acto de reparación. Con el objetivo de lograr la satisfacción, el Tribunal Administrativo del Chocó, a través de las sentencias de segunda instancia de los procesos de reparación a las víctimas de Bojayá, ordenó además de las indemnizaciones, reparaciones no pecuniarias consistentes en ceremonia de pedida de disculpas por parte de los altos mandos de las fuerzas militares y del 
gobierno, así como publicación de la sentencia en medios de difusión nacional. Esto constituye un gran esfuerzo por aplicar medidas de justicia restaurativa a las víctimas de Bojayá, pero cabe anotar que las mismas se dejaron sin efecto por el Consejo de Estado, en sentencias de tutela posteriores, lo que conlleva al retroceso del que habla Vásquez (2016).

Si bien se ha evolucionado en acciones de concertación con la comunidad, específicamente en la elaboración del programa de reparación integral; se debe avanzar en procesos consultivos que prioricen la trascendencia que tiene la vida para los afrodescendientes, la cual dista de la concepción que tiene el resto de la comunidad colombiana. Esto permite entender la destrucción espiritual que sufre un negro cuando le vulneran el derecho a la vida a un familiar o conocido, o por efecto del conflicto los desaparecen forzadamente, porque para los afros es indispensable enterrar a sus muertos y practicarles los rituales que su cultura establece como por ejemplo el "gualí o chiguaro"” a los niños.

\section{Acciones de rehabilitación}

Luego de la masacre, han llegado a Bojayá muchas instituciones, algunas de ellas presionadas por protagonismos a ultranza o por lógicas que no reconocen las necesidades y demandas propias de la población. El abordaje utilizado en este tipo de intervenciones también ha generado impactos psicosociales sobre la población, en particular porque han dado lugar a procesos de revictimización o victimización secundaria, propiciados tanto por nuevos maltratos y abusos, como por la exposición pública, permanente y recurrente que debe hacer la población de su tragedia y de su dolor (Bello et al., 2005). Lo anterior se propició porque la intervención realizada por el Estado no fue organizada, ni consultada con la comunidad, llegando entidades nacionales e internacionales, sin un programa definido, todas a querer hacer lo mismo, logrando empezar procesos que al final quedaron inconclusos; pero las secuelas psicológicas de las víctimas persisten en la actualidad.

Pese a lo anterior, y a raíz del acuerdo entre el Estado y las 1.100 víctimas, fue programado un acompañamiento psicosocial a la comunidad y en el proceso de exhumación, identificación y entrega de cuerpos en reducción esquelética, con el objetivo de reparar el daño psicológico y psicosocial de las personas víctimas.

Para cumplir con el objetivo reparador de las medidas de rehabilitación, el acompañamiento psicológico y de recuperación física debe ser permanente, con atención prioritaria y un enfoque étnico, que logre la reconstrucción y organización comunitaria, gravemente afectada porque muchos de los muertos eran líderes sociales.

\footnotetext{
${ }^{2}$ Un gualí es el velorio de un niño o "angelito", durante el cual se ponen cantos infantiles, rondas, la vestidura del niño es blanca y se le coloca corona. Cuando el niño es de brazos, al cadáver lo tiran de mano en mano y se tocan cánticos con instrumentos propios de la región. Es una celebración.
} 
Importancia de la diferenciación del enfoque diferencial étnico en el proceso de reparación en Bojayá, Chocó

La intervención física y psicológica debe necesariamente hacerse de manera consensuada y articulada entre las instituciones especializadas en el tema, para evitar repetir errores del pasado.

\section{Garantías de no repetición}

La justicia condenó al gobierno de la época por no garantizar la protección de la población, que aún espera más acciones de reparación. Fueron ocho alertas tempranas las que advirtieron la inminencia de un ataque sobre el centro poblado de Bellavista.

Los asesinatos, el confinamiento, los desplazamientos masivos, la
necesidad de ayudas alimentarias, la siembra de minas antipersonal
y el reclutamiento de menores, han vuelto a ser situaciones que
afectan la cotidianidad de un pueblo afro, mestizo e indígena que
cree y le apuesta a la paz y la reconciliación. La situación más
dramática se está viviendo en las comunidades del occidente del
municipio. Allí, los grupos al margen de la ley tienen afectadas
las actividades económicas que les dan el sustento alimentario a
los pueblos indígenas que habitan la zona. (Centro Nacional de
Memoria Histórica, 2019, p. 1)

Es precaria la implementación por el Estado de la garantía de no repetición, como lo mencionó el Centro Nacional de Memoria Histórica (2010), la población sigue confinada y con presencia de grupos al margen de la ley, con toques de queda que impiden la normal circulación de los habitantes para salir a sembrar o recolectar los alimentos para su subsistencia. Bojayá continúa siendo el paso de armas y drogas al Urabá antioqueño.

En este aspecto se exhorta al Estado para que implemente las medidas administrativas y judiciales pertinentes para restablecer el orden constitucional en esta comunidad y evitar la ocurrencia de una nueva tragedia.

Para finalizar, los intentos de reparación adelantados por el Estado Colombiano a las víctimas de Bojaya, para que se consideren ajustados a las necesidades de los afrodescendientes, deben comprender medidas consultadas, atender la dimensión colectiva tanto del daño, como de la reparación, basarse en el respeto por la identidad cultural del grupo étnico como colectividad y orientarse a las necesidades del grupo, tal como las define el mismo grupo. (Rodríguez \& Lam, 2011, p. 45) 
Ello, organizado desde sus estructuras administrativas de base, que para la comunidad afrodescendiente, son los consejos comunitarios, quienes están revestidos de autoridad para representarlos.

\section{Conclusiones}

El derecho internacional de los derechos humanos, sus órganos y tratados han avanzado en el objetivo de crear instrumentos para que las víctimas de graves violaciones a sus derechos humanos puedan obtener una reparación integral por el daño sufrido, sin embargo, si estos mecanismos no son ejecutados atendiendo el enfoque diferencial étnico, para las víctimas afrodescendientes o negras se hacen insuficientes. Es por ello por lo que, a la luz del derecho internacional de los derechos humanos, las sentencias de la Corte Interamericana de Derechos Humanos y la jurisprudencia interna colombiana, se concluye que el reconocimiento a las particularidades étnicas de las victimas afrodescendientes de graves violaciones de derechos humanos y la aplicación de políticas públicas afirmativas, ha generado un impacto relativamente bajo para la población negra víctima de la masacre de Bojayá.

Para que los procesos de reparación a las víctimas afrodescendientes del conflicto armado colombiano respondan a las particularidades étnicas de esta población minoritaria, es esencial que se escuche a las organizaciones de base - consejos comunitarios- los cuales a través de sus representantes tienen la autoridad para determinar qué medidas necesita la población afectada y de qué manera el Estado se las debe suministrar.

Hay que complementar medidas de desarrollo, con la obligación internacional de reparación a las víctimas de graves violaciones de derechos humanos. Lo anterior representa particular importancia para las comunidades negras, debido a la histórica discriminación y marginación a la que han estado sometidas, donde la presencia del Estado es pasiva y continúa la confluencia de grupos al margen de la ley.

Además de las indemnizaciones como medida de reparación, cuando se trata de víctimas afrodescendientes, se deben realizar reparaciones colectivas que enaltezcan la memoria de los fallecidos y permita la comunicación entre lo terrenal y lo espiritual que tradicional y culturalmente caracteriza a los afrodescendientes. Otorgar dinero por los daños materiales y morales sufridos, aunque es un derecho de las víctimas, en los afrodescendiente tiene una connotación diferente respecto al resto de la población, culturalmente se siente como si estuvieran recibiendo dinero a cambio de la vida de sus seres queridos, por lo cual ese dinero se considera "plata mala" y no se interioriza el recibirlo como una medida de reparación. En este sentido, se recomienda acompañar las indemnizaciones monetarias con profesionales en psiquiatría y psicología que oriente a los individuos beneficiarios de las mismas. 
Importancia de la diferenciación del enfoque diferencial étnico en el proceso de reparación en Bojayá, Chocó

Por último, se sugiere que en los procesos de reparación prevalezca lo colectivo, se priorice tanto el daño colectivo como la reparación colectiva, debido a que esta forma de abordar la reparación integral genera continuidad de la vida comunitaria, cultural y ancestral. Es importante resaltar que el Estado colombiano después del acuerdo de paz ha realizado pasos importantes en procura de adecuar el sistema de reparación efectuado en Bojayá a las normas y principios internacionales con una perspectiva étnica, lo cual logró con la firma el 29 de abril de 2018 del Plan Integral de Reparación Colectiva con la comunidad afro de Bellavista y que sigue avanzando en protocolizar un programa de reparación con el Consejo Comunitario Mayor de Bojayá y las comunidades indígenas de Bojayá. Habrá que esperar la implementación de estos programas de reparación, qué impactos genera en la comunidad y si son apropiados por la población como una reparación integral.

\section{Referencias}

Bello, M. N., Martín, E., Millán, C., Pulido, B. y Rojas, R. I. (2005). Bojayá: “memoria y río: Violencia política, daño y reparación”. Recuperado de https://bojayaunadecada.files. wordpress.com/2012/03/bojayamemoriayrio.pdf

Centro Nacional de Memoria Histórica de la Comisión Nacional de Reparación y Reconciliación. (2010). Informe del Grupo de Memoria Histórica de la Comisión Nacional de Reparación y Reconciliación. Bojayá: La guerra sin límites. Recuperado de http://www. centrodememoriahistorica.gov.co/descargas/informes2010/informe_bojaya.pdf.

Centro Nacional de Memoria Histórica de la Comisión Nacional de Reparación y Reconciliación. (2019). Bojayá: 17 años después, el clamor es el mismo. Recuperado de http: / / centrodememoriahistorica.gov.co/prueba-plantilla/

Comisión Interamericana de Derechos Humanos. (2011). Informe anual de la Comisión Interamericana de Derechos Humanos. Recuperado de http://www.oas.org/es/cidh/ expresion/docs/informes / anuales / 2012\%2003\%2021\%20Informe\%20Anual\%20 RELE\%202011\%20impresion.pdf

Comisión Interamericana de Derechos Humanos. (2013). Verdad, justicia y reparación: cuarto informe sobre la situación de [los] derechos humanos en Colombia. Recuperado de http: / / www. oas.org/es/cidh/docs/pdfs/justicia-verdad-reparacion-es.pdf

Consejo de Estado, Sala Contencioso Administrativo. (19 de octubre de 2007), Sentencia 29273. [MP E. Gil].

Consejo de Estado, Sala de lo Contencioso Administrativo. (14 de julio de 2016), Sentencia 35029. [MP H. RINCON ] 
Consejo de Estado, Consulta. (20 febrero de 2018), Sentencia 16996 [MP E. Gil]

Corte Constitucional. (14 de febrero de 2001), Sentencia C-169. [MP C. Gaviria].

Corte Constitucional. (4 de febrero de 2003), Sentencia C-067. [MP M. Monroy].

Corte Constitucional. (4 de diciembre de 2008), Sentencia C-1199. [MP N. Pinilla].

Corte Constitucional, (26 de enero de 2009), auto 005. [MP M. Cepeda].

Corte Interamericana de Derechos Humanos. (29 de julio de 1988). Caso Velásquez Rodríguez vs. Honduras.

Corte Interamericana de Derechos Humanos. (27 de noviembre de 1998), Caso Loayza Tamayo vs. Perú.

Corte Interamericana de Derechos Humanos. (3 de diciembre de 2001), Caso Cantoral Benavides vs. Perú.

Corte Interamericana de Derechos Humanos. (19 de noviembre de 2004), Caso Plan de Sánchez vs. Guatemala.

Corte Interamericana de Derechos Humanos. (15 de junio de 2005), Caso Moiwana vs. Suriname.

Corte Interamericana de Derechos Humanos. (28 de noviembre de 2007), Caso Pueblo Saramaka. vs. Surinam

Corte Interamericana de Derechos Humanos. (24 de agosto de 2010), Comunidad Indígena XákmokKásek. vs. Paraguay.

Corte Interamericana de Derechos Humanos. (27 de junio de 2012). Caso Pueblo Indígena Kichwa de Sarayaku vs. Ecuador

Corte Interamericana de Derechos Humanos. (20 de noviembre de 2013). Caso Comunidades Afrodescendientes desplazadas de la cuenca del río Cacarica (Operación Génesis) vs. Colombia.

Lozano, C. H. (2010). El daño ambiental en los programas de reparación colectiva para comunidades indígenas y afrodescendientes afectadas por el conflicto armado en Colombia, 17 International Law. Revista Colombiana de Derecho Internacional, 287-322 Recuperado de http: / / www.scielo.org.co/scielo.php?pid $=$ S1692 $-\quad 81562010000200008 \&$ script $={ }_{\text {sci }}$ arttext\#num9.

Ministerio del Interior. (Sin Fecha). Recuperado de https://gapv.mininterior.gov.co/sites/ default/files/cartilla_enfoque_diferencial_fin_1.pdf. 
Importancia de la diferenciación del enfoque diferencial étnico en el proceso de reparación en Bojayá, Chocó

Organización de Estados Americanos. (7 al 22 de noviembre 1969). Artículo 63. Competencia y funciones. Convención Americana sobre Derechos Humanos "Pacto de San José”. Recuperado de https://www.oas.org/dil/esp/tratados_B-32_Convencion_Americana_sobre_ Derechos_Humanos.htm

Rodríguez, C. y Lam, Y. (2011). Etnorreparaciones: la justicia colectiva étnica y la reparación a pueblos indígenas y comunidades afrodescendientes en Colombia. Recuperado de http://ww w.dejusticia.org/files/r2_actividades_recursos/fi_name_recurso.199.pdf.

Rojas, C. N. (2009). Las Reparaciones ante la Corte Interamericana de Derechos Humanos (19882007). Recuperado de http: / /www.corteidh.or.cr/tablas/r15428.pdf.

Sen, A. (2000). Desarrollo y libertad. México, D.F., México: Planeta.

Unidad de Víctimas. (2018). En Bojayá se firmó el primer Plan Integral de Reparación Colectiva para esa comunidad. Recuperado de http://www.unidadvictimas.gov.co/es/reparacioncolectiva/en-bojaya-se-firmo-el-primer-plan-integral-de-reparacion-colectiva-para-esa.

Vásquez, J. P. (2016). La Constitucionalización del Juez Administrativo en Colombia. Bogotá, Colombia: Grupo Editorial Ibáñez. 